Benha Journal of Applied Sciences (BJAS)

Vol. (4) Issue (1) (2019), (97-102) print: ISSN 2356-9751

online: ISSN 2356-976x

\title{
Prevalence of Autistic Spectrum Disorders in Preschool Children in Qalyubiya Governorate E. A.Abu Amer ${ }^{1}$, S.T.El Bakry ${ }^{2}$, A.A.Sobeih ${ }^{1}$, R.M.Zakaria ${ }^{1}$ and G.M.Reda ${ }^{1}$ \\ ${ }^{1}$ Pediatrics Dept., Faculty of Medicine, Benha Univ., Benha, Egypt \\ ${ }^{2}$ PsychiatryDept.,Faculty of Medicine,Benha Univ., Benha, Egypt \\ E-Mail:Gadareda2017@yahoo.com
}

\begin{abstract}
Autism spectrum disorder is a neurodevelopmental disorder with a strong genetic basis. This study has been conducted to determine prevelance and the possible risk factors of autism. . This studty is a retrospective study that

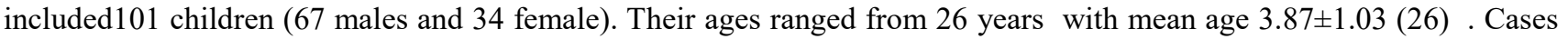
was collected from KGs, special centers and psychiatry clinic, Pediatric Department, Benha univeristiy hospital and Benha specialized Hospital. The included child was subjected to: the followings tools: Confirmation of diagnosis using DSMV criteria,, and assessment of severity of autistic symptoms using childhood autism rating scale (CARS). A small structured questionnaire and complete medical history stressing on developmental, therapeutic and behavioral histories were also developed and administered. ASD prevalence was 1 in51 childrenThe current study was conducted on 101 autistic children, their ages range from $2-6$ years with a mean value of $3.87 \pm 1.03$ years, 66.3 of autistic children were males and 33.7 were females, with a male/female ratio of 2:1; ( $>0.05$ all).Advanced paternal age (father, P35 years) at birth was found in $91 \%$ of cases and the difference was statistically significant. Positive family history was found to be statistically unsignificant. As regards natal factors, a history of low birth weight, delivery by ceserian section were significantly higher among cases. Also postnatal factors as history of hypoxia, resuscitation and history of jaundice were considered significantly risk factors for autism $(\mathrm{p}=0.000)$.
\end{abstract}

\section{Introduction}

Extreme introvertedness range jumble is An neurodevelopmental issue with a solid hereditary foundation. ASD is clinically introduce in front of the agdistis from claiming 3 quite some time for side effects concerning primarily two regions which are restricted, tedium examples about behaviors, interests, alternately activities, Furthermore persistency deficits clinched alongside social correspondence Furthermore social communication [1]. ASD pervasiveness agreeing the extreme introvertedness What's more developmental Disabilities screening (ADDM) reconnaissance might have been 14.7 for every 1,000 (one in 68) Around Youngsters ageold 8 a considerable length of time in the united States, likewise ASD pervasiveness might have been 23 . 7 for every 1,000 (one for 42) around young men Furthermore 5. 3 for every 1,000 (one On 189) Around young ladies [2].

The accounted for predominance from claiming ASDs need expanded markedly Throughout days gone by 3 decades. Those present ASD pervasiveness to know youngsters is assessed on a chance to be give or take $1.4 \% \mathrm{Be}$ that as need been accounted for to make Concerning illustration helter skelter Similarly as $2.6 \%$ [3].

Those pathogenesis of this condition takes under record heredity alongside those environ $\neg$ ment playing An part as an epigenetic phenotype trigger. Individualized hereditary predispositions helped Eventually Tom's perusing trigger elements Likewise infections, toxins, trauma also how camwood disable embryogenesis and additionally peri What's more postnatal improvement of the tyke. Maternal hereditary elements and in addition Ecological factors influencing the mothball previously, then Throughout pregnancy likewise appear to be will assume a part in the pathogenesis for ASD [4].

Those vicinity from claiming Ecological danger figures Throughout incredulous periods for embryonic/fetal improvement might impact those safe framework in the mother, pushing restricted or systemic incendiary reactions with those discharge about cytokines What's more hormonal molecules, which to turn, by means of neuroimmunomodulatory reactions What's more crosstalk the middle of circulative Furthermore neural systems, might disable meandering development, neuronal plasticity, What's more neuroglial work in the embryo/fetus [5].

Point of the contemplate might have been should study the predominance What's more danger figures from claiming extreme introvertedness range issue for preschool kids Previously, Qalyubiya Governorate.

\section{Subjects and methods}

This study is a retrospective study that included 101 children (67 males and 34 female). Their ages ranged from 26 years with mean age $3.87 \pm 1.03$ [26] . Cases was collected from KGs, special centers and psychiatry clinic, Pediatric Department, Benha univeristiy hospital and Benha specialized Hospital .

\subsection{Inclusion criteria}

Among these children (5000) it was found that 101 children was diagnosed as one of the autistic disorder according to DSMV (APA 2013) .

They were67 males(66.3\%) and 34 female(33.7\%).

Their ages ranged from 26 years with mean age $3.87 \pm 1.03[26]$. 


\subsection{Methods}

I All cases were subjected to the following Detailed history taking with special emphasis on; onset,bcourse and duration of the disease and age, sex of the patient, consanguinity.

Antenatal or maternal history age at patient's birth, history of threatened abortion, any fetal loss, parity, exposure to Xray during pregnancy, exposure to heavy metals chronic illness as hypertension, Diabetes mellitus (DM), infections or hospitalizations during pregnancy, medications (e.g. antiepileptic drugs, antithyroid drugs, antiD injection ........).

Natal and postnatal history including, gestational age, complication during Labour or delivery, history of prematurity or intrauterine growth retardation, gestational age at birth, birth weight, perinatal problems and postnatal course especially occurrence of neonatal hypoxia, resuscitation, pallor and jaundice.

Developmental history (both mental and motor) age of sitting up without support, walking unassisted, first spoken word, combining words, accurate details of cognitive abilities, gross and fine motor functions, feeding disorders, abnormal sleep patterns and history of vaccination.

Past history including major childhood illnesses, any previous therapies used to treat the child's condition.
Family history for any similar conditions, any genetic diseases and other psychological or mental disorders in the Family .

sociodemographic and behavioral characteristics of the parents (Age of the parent, education level, occupation) Nutritional history Breast feeding or NOT .

consanguinity between parents .

II.Clinical examination stressing on neurological examination.

III.Psychiatric assessment as follows

A IQ test assessment using StanfordBient Intelligence Scale (1986).

BDiagnosis of autism using the DSMV criteria (APA 2013)

CThe severity of autism was evaluated using the childhood autism rating scale (CARS) which rates the child on a scale from 1 to 4 in each of 15 areas

According to the scale, scores of $1529.5=$ non autietic , 30-36.5 indicate mild to moderate autism and scores of 37-60 indicate severe autism(Oznoff $S$ et al.,2005).

\subsection{Statistical analysis}

The clinical data were recorded on a report form. These data were tabulated and analyzed using the computer program SPSS (Statistical package for social science) version 20 to obtain adescriptive data.

\section{Results}

Tables(1) Characteristic features of the studied group according to sociodemographic data.

\begin{tabular}{|c|c|c|}
\hline & No (101) & $\%$ \\
\hline \multicolumn{3}{|l|}{ Sex } \\
\hline Male & 67 & 66.3 \\
\hline Female & 34 & 33.7 \\
\hline Age /years mean \pm SD (Range) & \multicolumn{2}{|c|}{$3.87 \pm 1.03(26)$} \\
\hline Weight $\quad$ mean \pm SD (Range) & \multicolumn{2}{|c|}{$18.77 \pm 4.48(2.530)$} \\
\hline \multicolumn{3}{|l|}{ Father education } \\
\hline University & 18 & 17.8 \\
\hline Primary & 31 & 30.7 \\
\hline Read and write & 41 & 40.6 \\
\hline None & 11 & 10.9 \\
\hline \multicolumn{3}{|l|}{ Father job } \\
\hline Working & 95 & 94.1 \\
\hline No & 6 & 5.9 \\
\hline \multicolumn{3}{|l|}{ Mother education } \\
\hline University & 19 & 18.8 \\
\hline Primary & 33 & 32.7 \\
\hline Read and write & 34 & 33.7 \\
\hline None & 15 & 14.9 \\
\hline \multicolumn{3}{|l|}{ Mother job } \\
\hline Working & 50 & 49.5 \\
\hline No & 51 & 50.5 \\
\hline \multicolumn{3}{|l|}{ Consanguinity } \\
\hline Yes & 37 & 36.6 \\
\hline No & 64 & 63.4 \\
\hline
\end{tabular}


Tables(2) Characteristic features of the studied group according to environmental factors.

\begin{tabular}{|c|c|c|}
\hline Environmental factors & No (101) & $\%$ \\
\hline \multicolumn{3}{|l|}{ Prenatal factors } \\
\hline \multicolumn{3}{|l|}{ History of infection } \\
\hline Yes & 25 & 24.8 \\
\hline No & 76 & 75.2 \\
\hline Age of father $\quad$ mean \pm SD (Range) & \multicolumn{2}{|c|}{$36.07 \pm 5.57(2552)$} \\
\hline Age of mother mean \pm SD (Range) & \multicolumn{2}{|c|}{$30.91 \pm 5.34(2041)$} \\
\hline \multicolumn{3}{|l|}{ Type of maternal disease (45) } \\
\hline Anemia & 30 & 66.7 \\
\hline Htn & 7 & 15.6 \\
\hline Autoimmune & 1 & 2.2 \\
\hline Depression & 7 & 15.6 \\
\hline DM & 15 & 33.3 \\
\hline \multicolumn{3}{|l|}{ History of drugs used during pregnancy } \\
\hline Yes & 25 & 24.8 \\
\hline No & 76 & 75.2 \\
\hline \multicolumn{3}{|c|}{ Ho } \\
\hline Yes & 9 & 8.9 \\
\hline No & 92 & 91.1 \\
\hline \multicolumn{3}{|l|}{ Perinatal \& neonatal factors } \\
\hline \multicolumn{3}{|l|}{ Mode of delivery } \\
\hline CS & 58 & 57.4 \\
\hline NVD & 43 & 42.6 \\
\hline \multicolumn{3}{|l|}{ Complications of delivery (27) } \\
\hline Premature & 18 & 66.7 \\
\hline Obstructed & 6 & 22.2 \\
\hline Cord around neck & 3 & 11.1 \\
\hline GA $\quad \operatorname{mean} \pm$ SD (Range) & \multicolumn{2}{|c|}{$36.16 \pm 1.56(3340)$} \\
\hline Birth weight $\quad$ mean \pm SD (Range) & \multicolumn{2}{|c|}{$2.75 \pm 0.47(1.54 .0)$} \\
\hline \multicolumn{3}{|l|}{ Postnatal factors } \\
\hline \multicolumn{3}{|l|}{ History of obligatory immunization } \\
\hline Yes & 99 & 98.0 \\
\hline No & 2 & 2.0 \\
\hline \multicolumn{3}{|l|}{ Any child associated disease } \\
\hline Yes & 71 & 70.3 \\
\hline No & 30 & 29.7 \\
\hline
\end{tabular}

Table (3) Characteristic features of the studied group according to degree of disease and severity level.

\begin{tabular}{lccc}
\hline & No (101) & \% \\
\hline Degree (CARS) & mean \pm SD (Range) & \multicolumn{2}{c}{$35.27 \pm 9.11(2257)$} \\
Severity levels & $\mathbf{n}(\%)$ & 44 & 43.6 \\
Mild & Moderate & 25 & 24.8 \\
Severe & 32 & 31.7 \\
\hline
\end{tabular}

\section{Discussion}

The current ponder might have been led with respect to 101 mentally unbalanced children, their ages go from2 - 6 a considerable length of time for a mean quality about $3.87 \pm 1.03$ years, 66. 3 of mentally unbalanced Youngsters were guys and 33. 7 were females, with An male/female proportion for 21; ( $\mathrm{p}>0$. 05 all).
Extreme introvertedness by and large is usually accounted to expositive expression with need higher occurrence done guys over females.

In understanding for our effects [6] Werling and Geschwind indicated that ASD need An striking male inclination On pervasiveness with roughly 4 influenced guys for each 1 influenced female. 
In the current consider a few danger figures to extreme introvertedness were assessed.

Those effects indicated that 36.6 of the examined mentally unbalanced patients need certain history from claiming parental association Furthermore 63. 4 need negative history from claiming association. There might have been no statistically noteworthy contrasts Concerning illustration respects the formerly said factor; $(\mathrm{p}>0.05)$.

Comparative discoveries were accounted for Eventually Tom's perusing a significant number writers as [7], [8].

Mosrati et al. [9] illustrated that association expands familial grouping from claiming various inherited ailments inside the same gang.

In the present study, there might have been statistically no critical Contrast Concerning illustration views those maternal period at origination in the mentally unbalanced children; $(p>0.05)$.

This might have been in understanding for Lauritsen et al. [10] who discovered that the danger of extreme introvertedness might have been not connected with expanding maternal period. Bilder et al. [7] discovered that there might have been An critical cooperation between propelled maternal agdistis Also hazard from claiming ASDs.

Our consider indicated that secondary father tan agdistis toward conception for mentally unbalanced know youngsters was $(35.25 \pm 6.01)$ and it might have been statistically significant; $(\mathrm{p}<0.05)$.

In understanding on these comes about Kolevzon et al. ,[11] discovered that the parenteral trademark connected with a expanded hazard of extreme introvertedness What's more a mental imbalance. Range issue incorporate propelled maternal age, Also fatherly agdistis.

In the current study, there might have been statistically critical of secondary social class as The greater part for their guardians need aid professional (doctors and engineers) $(\mathrm{p}<0.05)$. Nursery worker et al. , [12]found that helter skelter socioeconomic status might have been normal done groups with. Mentally unbalanced Youngsters. On the different hand, Reichen berg et al. ,[13] who discovered that over as far back as 25years an expanding extent about cases needed been found in the low socioeconomic aggregation.

Those present study showed non noteworthy contrasts in the frequency about certain family history around mentally unbalanced kids.

These discoveries are in understanding with Klauck et al. , [14] announced that clinched alongside a few cases, guardian What's more different relatives from claiming mentally unbalanced know youngsters indicate gentle impairments for social Also open abilities.

As opposed of the display study, de long Furthermore Nohna [15] discovered that full of feeling or passionate issue happen a greater amount every now and again over Normal inside groups about individuals for extreme introvertedness.

This investigation uncovered no huge commitment from claiming hereditary variable of the etiology about a mental imbalance. So, it shows up that should date, best a little rate of mentally unbalanced issue need been connected with particular hereditary alternately chromosomal abnormalities. Actually then, we might conjecture that inside this group, more than person hereditary locus will be discovered.

As stated by autos scores $31.7 \%$ from claiming our cases required extreme level of autism, 24. 8\% needed moderate degree, and $43.6 \%$ required gentle degree. Comparable discoveries were news person Toward A large number creators.

In the current examine The majority for our patients exhibited during agdistis for 26 quite some time with imply agdistis $3.87 \pm 1.03$ (26).

Similarly as respects natal factors, history about low conception weight demonstrated that there might have been no statistically significant; $(p>0.05)$. Schendel and Bhasin [16] demonstrated no statistically importance between hazard from claiming a mental imbalance Furthermore low conception weight male kids without other developmental inability. [17] viewed as conception weight may be the net come about for no less than three variables hereditary Growth potential, span of the pregnancy, Also rate from claiming fetal Growth What's more suggester a solid companionship between conception weight What's more extreme introvertedness.

Our effects managing postnatal Components as history about hypoxia, resuscitation, historical backdrop about neonatal jaundice were also statistically essentially expanded Previously, mentally unbalanced patients $(p=0.000)$. [11], recommended the vicinity from claiming no heritable prenatal, Furthermore perinatal danger figures for extreme introvertedness. A plausibility underpinned via consider Bolton et al. [18] showed an affiliation the middle of extreme introvertedness Furthermore obstetric complications, prenatal alternately intrapartum utilization of medications. Burd et al. [19] accounted that perinatal danger figures Similarly as breech presentation, low apgar score (67) In $5 \mathrm{~min}$, low conception weight $(62500 \mathrm{~g})$, gestational agdistis during conception from claiming less 35 weeks, Furthermore being little to gestational agdistis were connected with a statistically essentially expanded hazard for extreme introvertedness.

The current study indicated that sure maternal history of immune system ailments might have been for measurable significance; $(p<0.05)$. Vinet et al. [20] recommended that there will be twofold danger for ASD Previously, know youngsters for moms for sle 
over the individuals for controls. Chen et al. [21] suggested that no statistically noteworthy Contrast over danger from claiming a mental imbalance in the posterity for maternal SLE, incendiary inside disease, idiopathy (ITP), psoriasis Furthermore rheumatoid joint inflammation.

Those exhibit ponder indicated that there might have been no statistically noteworthy Likewise respects the maternal infection, pills intake, infections Furthermore dying Throughout pregnancy; ( $p>0.05$ to all).

In understanding for our results, Atladóttir et al. [22] proposed that gentle infections, febrile episodes, or utilization of antibiotics Throughout pregnancy would not solid danger figures to ASD What's more puerile extreme introvertedness. Langridge et al. [23] recommended no affiliation from claiming ASD with Possibly maternal viral alternately bacterial infections. Outcomes demonstrated that maternal infections such as diabetes, a few immune system diseases, infections What's more incendiary sicknesses Throughout pregnancy needed been connected with an expanded rate from claiming ASD in the posterity. Also, a few medications What's more chemicals required been connected with an expanded rate for ASD Emulating intrauterine purposes of presentation.

The display examine demonstrated that there might have been statistically critical Concerning illustration views with gestational diabetes. Gestational diabetes need been connected with Different unfriendly pregnancy conclusions.

Those display examine indicated that there might have been no statistically noteworthy Concerning illustration of immunization.

In understanding for our results, recommended that vaccinations would not connected with the improvement of ASD. Furthermore, the parts of the immunizations (thimerosal or mercury) alternately different immunizations (MMR) need aid not connected with the advancement from claiming ASD. In contrast, it might have been Awhile ago recommended that those measles, mumps Furthermore rubella immunization (MMR) might have been a workable reason for extreme introvertedness [6].

\section{References}

[1] F. R.volkmar and J. C. McPartland,From Kanner to DSM5 autism as an evolving diagnostic concept, Annu. Rev. Clin. Psychol.,vol. 10, pp. 193-212, 2014.

[2] J. Baio,Prevalence of autism spectrum disorder among children aged 8 yearsautism and developmental disabilities monitoring network, 11 sites, United States, 2014.

[3] V. A. Mysore,Autism spectrum disorders Phenotypes, mechanisms and treatments, Indian J. Med. Res.,vol. 144(6), p. 948, 2016.
[4] V. Mazina,Epigenetics of autismrelated impairment copy number variation and maternal infection., J. Dev. Behav. Pediatr. JDBP,vol. 36 (2), pp. 61-67, 2015.

[5] C. Gottfried, V. BambiniJunior, F. Francis, R. Riesgo, and W. Savino, The impact of neuroimmune alterations in autism spectrum disorder, Front. psychiatry,vol. 6(121), 2015.

[6] D. M. Werling and D. H. Geschwind,Sex differences in autism spectrum disorders, Curr. Opin. Neurol.,vol. 26(2), p. 146, 2013.

[7] D. Bilder, J. PinboroughZimmerman, J. Miller, and W. McMahon,Prenatal, perinatal, and neonatal factors associated with autism spectrum disorders, Pediatrics,vol. 123(5), pp. 1293-1300, 2009.

[8] F. ElBaz, N. A. Ismael, and S. M. N. ElDin,Risk factors for autism An Egyptian study, Egypt. J. Med. Hum. Genet.,vol. 12(1), 2011.

[9] M. A. Mosrati .,Genome wide analysis in a family with sensorineural hearing loss, autism and mental retardation, Gene,vol. 510(2), pp. 102-106, 2012.

[10]M. B. Lauritsen, C. B. Pedersen, and P. B. Mortensen,Effects of familial risk factors and place of birth on the risk of autism a nationwide registerbased study, J. Child Psychol. Psychiatry,vol. 46(9), pp. 963-971, 2005.

[11]A. Kolevzon, R. Gross, and A. Reichenberg,Prenatal and perinatal risk factors for autism a review and integration of findings, Arch. Pediatr. Adolesc. Med.,vol.161(4), pp. 326-333, 2007.

[12]H. Gardener, D. Spiegelman, and S. L. Buka,Prenatal risk factors for autism comprehensive metaanalysis, Br. J. psychiatry,vol.195(1), pp. 7-14, 2009.

[13]A. Reichenberg .,Advancing paternal age and autism, Arch. Gen. Psychiatry,vol. 63(9), pp. 10261032, 2006.

[14] S. M. Klauck, Genetics of autism spectrum disorder, Eur. J. Hum. Genet.,vol. 14(6), p. 714, 2006.

[15]R. De Long and C. Nohna,Psychiatric family history and neurological disease in autistic spectrum disorders, Dev. Med. Child Neurol.,vol. 36(5), pp. 441-448, 1994.

[16]D. Schendel and T. K. Bhasin,Birth weight and gestational age characteristics of children with autism, including a comparison with other developmental disabilities, Pediatrics,vol. 121(6), pp. 1155-1164, 2008.

[17] M. Larsson, B. Weiss, S. Janson, J. Sundell, and C.G. Bornehag,Associations between indoor environmental factors and parentalreported autistic spectrum disorders in children 6-8 years of age, Neurotoxicology,vol. 30(5), pp. 822-831, 2009.

[18] P. F. Bolton, I. CarcaniRathwell, J. Hutton, S. Goode, P. Howlin, and M. Rutter,Epilepsy in autism 
features and correlates, Br. J. Psychiatry,vol. 198(4), pp. 289-294, 2011.

[19] L. Burd, R. Severud, J. Kerbeshian, and M. G. Klug,Prenatal and perinatal risk factors for autism, J. Perinat. Med.,vol. 27(6), pp. 441-450, 1999.

[20]É. Vinet.,Increased risk of autism spectrum disorders in children born to women with systemic lupus erythematosus results from a large population-based cohort, Arthritis Rheumatol.,vol. 67(12), pp. 3201-3208, 2015.

[21] S. Chen .,Maternal autoimmune diseases and the risk of autism spectrum disorders in offspring a systematic review and metaanalysis, Behav. Brain Res.,vol.296, pp. 61-69, 2016.

[22] H. Ó. Atladóttir, T. B. Henriksen, D. E. Schendel, and E. T. Parner,Autism after infection, febrile episodes, and antibiotic use during pregnancy an exploratory study, Pediatrics,vol.130(6), pp. e1447e1454, 2012.

[23] A. T. Langridge .,Maternal conditions and perinatal characteristics associated with autism spectrum disorder and intellectual disability, PLoS One,vol. 8(1), p. e50963, 2013. 